\title{
A review of the use of gold catalysts in selective hydrogenation reactions
}

\author{
Lynsey McEwana, Melissa Julius ${ }^{a *}$, Stephen Roberts ${ }^{a}$ and Jack C.Q. Fletcher ${ }^{a}$ \\ www.goldbulletin.org
}

\begin{abstract}
The field of gold catalysis has been a lively area of research for the past two decades and gold catalysts are now an established 'best choice' for many oxidation reactions. Most well known for its performance in selective and preferential oxidation reactions, gold has more recently found potential in selective hydrogenation reactions. In this work the recent developments using gold and gold-promoted catalysts for selective hydrogenation reactions are reviewed: the use for chemoselective hydrogenation of $\alpha, \beta$-unsaturated aldehydes and, in particular, the excellent selectivity exhibited for the selective partial hydrogenation of alkyne, alkadiene and alkene $C_{2}-C_{6}$ hydrocarbon streams.
\end{abstract}

\section{Introduction}

For many years gold was believed to be relatively inactive as a catalyst. This apparent lack of activity is most likely due to the fact that traditional supported catalysts were prepared via an impregnation method, which generally produces gold particles outside the nanosize range required for activity. Due to the inability of bulk gold to chemisorb typical reactant molecules, these larger particles provided a relatively inactive catalyst (1). Despite this, several studies were carried out in the 1970's to assess the potential of gold for heterogeneous catalysis. Researchers demonstrated that gold was able to catalyse hydrogenation (2-5) and oxidative dehydrogenation reactions (6) as well as hydrogen exchange (7) and hydrocracking (8), however the gold catalysts performed poorly in comparison to well established platinum and palladium catalysts and were therefore not pursued as a practical alternative.

Then in the 1980's two important discoveries revived interest in gold as a catalyst. Haruta and coworkers $(9,10)$ found that gold, when deposited as nanoparticles on a support using techniques such as deposition-precipitation and co-precipitation, was very active for $\mathrm{CO}$ oxidation at ambient temperature as well as at temperatures as low as $-76^{\circ} \mathrm{C}$. Whilst Hutchings (11-14) demonstrated that supported gold chloride was the most effective catalyst for ethyne hydrochlorination.

Subsequently, the volume of research into catalysis by gold has grown rapidly. The majority of research has focused on CO oxidation, with debates over the nature of the active site and mechanism of oxidation continuing today. This has, until recently, overshadowed other promising applications for gold as a catalyst; particularly it's potential for hydrogenation reactions. This review aims to highlight the range of hydrogenation reactions for

\footnotetext{
a Centre for Catalysis Research, Department of Chemical Engineering, University of Cape Town, Cape Town, Rondebosch, 7701, South Africa

* Corresponding author: Tel: +27 02165037 21, Fax: +27 021650 4051, E-mail: julius.melissa@gmail.com
} 
which gold, as well as gold-promoted catalysts, show potential: in particular, to discuss in detail the excellent selectivity exhibited by these catalysts for the selective hydrogenation of alkynes and alkadienes in a mixture with alkenes.

\section{Hydrogen adsorption on gold}

The interaction of hydrogen with gold is significant in understanding how the hydrogen molecule is activated/dissociated on gold catalysts. Gold has a limited ability to chemisorb hydrogen as compared to the platinum group metals, and as such it is a less active catalyst for reactions involving the dissociation of hydrogen (15). It is accepted that chemisorption on the bulk metal does not occur (16), while on rough surfaces and thin unsintered gold films the chemisorption of hydrogen atoms does occur, but only at low temperatures and desorption occurs quickly on heating (15).

Few studies have investigated the interaction of hydrogen with gold. Sault et al. (17) observed that no hydrogen chemisorption occurs on the $\mathrm{Au}(110)$ $(1 \times 2)$ surface - the hydrogen atoms adsorb and desorb again at $226 \mathrm{~K}$. Investigating the interaction on thin, unsintered gold films, Stobinski et al. (18) observed the dissociative chemisorption of hydrogen molecules and suggested that hydrogen reacts with the low coordinated gold atoms on corner and edge sites. The hydrogen coverage at $0.3 \mathrm{~Pa}$ and $78 \mathrm{~K}$ was less than $1.5 \%$.

In the case of supported gold nanoparticles, dissociative adsorption of hydrogen is implied by the observed activity in hydrogenation reactions. Weak, reversible adsorption of hydrogen was detected by Vannice et al. (19) on $30 \mathrm{~nm}$ gold on titania at 298 and $473 \mathrm{~K}$. A coverage of approximately $1 \%$ of the total amount of gold was achieved. The hydrogen uptake was found to be greater at $473 \mathrm{~K}$ than at $300 \mathrm{~K}$, hence, it was suggested that the adsorption of hydrogen is an activated process and most likely associated with hydrogen dissociation. Jia et al. (20) employed smaller gold particles $(3.8 \mathrm{~nm}$ gold on alumina) and observed that $14 \%$ of the surface atoms adsorbed hydrogen almost irreversibly at $273 \mathrm{~K}$.

The gold size dependency of activity suggests that the chemisorption of hydrogen may be dependent on particle size effects. Recently, comprehensive studies by Bus et al. $(21,22)$ have demonstrated this through a combination of experiments using
$\mathrm{Au} / \mathrm{Al}_{2} \mathrm{O}_{3}$ catalysts comprising of different gold particles sizes $(1-10 \mathrm{~nm})$. It was concluded that hydrogen dissociatively adsorbs only on the corners and edges of the supported gold. The gold atoms in these positions dissociate the hydrogen, which does not spill over to the face sites. Gold atoms at the corner and edge sites have a low coordination number compared with face atoms, and thus have a more reactive d-band; as a result these atoms are able to interact more easily with adsorbates such as hydrogen (22). Thus, smaller gold particles having a higher fraction of low coordinated gold atoms present on corners and edges will have an increased average number of gold atoms active for hydrogen dissociation. This is in agreement with recent work presented by Serna et al. (23) and Boronat et al. $(24,25)$.

Fujitani etal. (26) experimentally finds no HD formation between $\mathrm{H}_{2}$ and $\mathrm{D}_{2}$ other than in the presence of $\mathrm{Au}$ supported on $\mathrm{TiO}_{2}\left(\mathrm{Au} / \mathrm{TiO}_{2}(110)\right)$ - no HD formation was observed at any single-crystal surface (Au(111), $\mathrm{Au}(311)$ and $\left.\mathrm{TiO}_{2}(110)\right)$. This suggests that the gold metal and $\mathrm{TiO}_{2}$ surface did not dissociate the $\mathrm{H}_{2}$ whereas the $\mathrm{Au} / \mathrm{TiO}_{2}$ surface did dissociate the $\mathrm{H}_{2}$. Furthermore, the rates of HD formation increased sharply below a gold particle size of $2 \mathrm{~nm}$, while TOFs were almost constant regardless of the mean gold particle diameter, suggesting $\mathrm{H}_{2}$ dissociation does take place on the surface and in close proximity to the gold/metal oxide interface. Additionally, the $\mathrm{H}_{2}$ dissociation was shown not too correlate to a change in the fraction of edge and corner sites nor to a change in the electronic nature induced by the quantum size effect.

Evidence exists for chemisorbed alkenes, alkadienes and alkynes on gold $(27,28)$, which probably alludes to the hydrogenation reaction going by the LangmuirHinselwood mechanism, although this does not discount the possibility that the reaction may also go by a Rideal-Eley mechanism.

\section{Supported gold catalysts for hydrogenation reactions}

Studies as early as 1973 by Bond and co-workers reported that supported gold was an active hydrogenation catalyst for olefinic hydrocarbons $(2,3)$. Supported on silica or $\gamma$-alumina, gold catalysts prepared by impregnation were effective for the hydrogenation of 1-pentene at $373 \mathrm{~K}(2-4)$. However, the activity was significantly lower than that observed for catalysts comprising of group VIII metals. Similar 
gold supported catalysts were also tested in the hydrogenation of 1,3-butadiene $(2,5)$ and 2-butyne (2), the catalysts were almost completely selective to the formation of butene and were active for the isomerisation to butene isomers but did not catalyse the total hydrogenation to the alkane. Despite these early discoveries, the field of gold catalysis remained mostly dormant for many years until the discoveries of the 1980's revived interest in the field.

\subsection{Chemoselective hydrogenation}

Much research has recently been reported on the effectiveness of supported gold for the selective hydrogenation of multifunctional organic molecules, such as the chemoselective hydrogenation of $\alpha, \beta$-unsaturated aldehydes to the unsaturated alcohol in preference to the saturated aldehyde or saturated alcohol (29-36). Industrial interest in the production of unsaturated alcohols is based on their use as fragrances and as intermediates in the pharmaceuticals industry (29).

The reaction scheme is illustrated for the $\mathrm{C}_{3} \alpha, \beta$ unsaturated aldehyde, acrolein, in Figure 1. The hydrogenation of the $\mathrm{C}=\mathrm{C}$ bond (pathway ' $\mathrm{b}$ ') is favoured over hydrogenation of the $\mathrm{C}=\mathrm{O}$ bond (pathway 'a') for both thermodynamic and kinetic reasons (29), and as such the selectivity problem

Figure 1

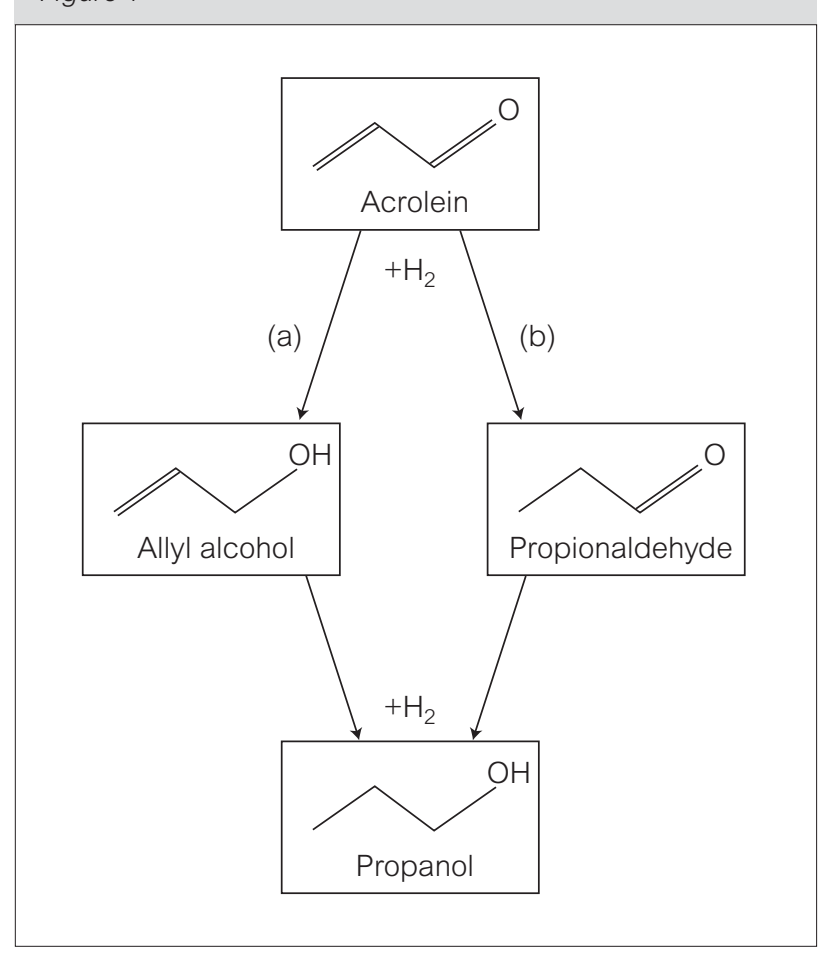

Reaction scheme for acrolein hydrogenation of this type of reaction is to obtain preferential hydrogenation of the $\mathrm{C}=\mathrm{O}$ bond. The noted advantage of using gold catalysts is the ability to selectively hydrogenate the $\mathrm{C}=\mathrm{O}$ group in preference to the $\mathrm{C}=\mathrm{C}$ group. However, the exact influence of factors such as gold particle size and choice of support on the activity and selectivity is not yet apparent. This field of research has been reviewed extensively elsewhere (29-30). Gold's success in priority reduction of the $\mathrm{C}=\mathrm{O}$ group may be related to the chemisorption of $\mathrm{CO}$. Investigations of the influence of metal-support interactions (MSI) in Pt/ $\mathrm{TiO}_{2}$ on the hydrogenation of various aldehydes and ketones have indicated that when MSI are induced in the catalyst, resulting in reduced chemisorption of $\mathrm{CO}$ and $\mathrm{H}_{2}$, the selectivity to the hydrogenation of the $\mathrm{C}=\mathrm{O}$ group was significantly increased $(37,38)$.

Bailie and co-workers showed that $\mathrm{Au} / \mathrm{ZnO}$ and $\mathrm{Au} / \mathrm{ZrO}_{2}$ were selective for the hydrogenation of crotanaldehyde to produce crotyl alcohol (31, 32). An enhanced activity was observed for some thiophene treated catalysts, the first observation of a promotional effect by sulphur for a gold catalyst (31). In a further study, it was observed that the sulphur promotion was associated only with smaller gold nanoparticles ( $<10 \mathrm{~nm}$ ) and the high selectivity (ca. $80 \%$ ) of $\mathrm{Au} / \mathrm{ZnO}$ (5 wt \%) was attributed to large gold particles of diameter 10-20 nm (32). Studies by Claus and co-workers (33-35) investigated the selective hydrogenation of acrolein using Au/ $\mathrm{ZrO}_{2}, \mathrm{Au} / \mathrm{ZnO}, \mathrm{Au} / \mathrm{TiO}_{2}, \mathrm{Au} / \mathrm{SiO}_{2}$ and bimetallic $\mathrm{Au}-\ln / \mathrm{ZnO}$. The choice of support was found to affect the morphology of the gold nanoparticles and the edge sites were concluded to be the active site favouring the adsorption of the $\mathrm{C}=\mathrm{O}$ group. Thus, the choice of support had an effect on activity, with higher activities observed for catalysts with more rounded particles (34). The bimetallic Au-In/ZnO catalysts performed particularly well, producing allyl alcohol with a selectivity of $63 \%$ (35). Similar research (36) has focused on the hydrogenation of crotanaldehyde and cinnamaldehyde over goldsupported iron oxides. For the size range studied (4-15 nm) differences in selectivity observed were attributed to the morphology of gold particles, with no significant influence of gold particle size.

More recently, researchers have investigated the more challenging chemoselective hydrogenation of aromatic nitro-compounds to the corresponding amines (39-43). Chen and co-workers (39) prepared a novel $\mathrm{Au} / \mathrm{SiO}_{2}$ catalyst and tested the reduction of various aromatic nitro-compounds. The resulting 
high selectivity to the corresponding amine showed that gold catalysts can selectively reduce nitrogroups to amine groups in the presence of other easily reducible groups, such as $\mathrm{C}=\mathrm{C}$ and $\mathrm{C}=\mathrm{O}$, making gold a potentially useful catalyst for this type of reaction. Similar research by Corma and Serna (40) employed $\mathrm{Au} / \mathrm{TiO}_{2}$ and $\mathrm{Au} / \mathrm{Fe}_{2} \mathrm{O}_{3}$ to produce functionalised anilines by the chemoselective hydrogenation of aromatic nitro-compounds. Further studies (41) focused on the synthesis of oximes from $\alpha, \beta$-unsaturated nitro-compounds, and found gold catalysts to be a promising alternative to the current method of using stoichiometric amounts of organic hydrogen donors.

Other related studies, investigated the selective gas phase hydrogenation of aromatic nitro-groups in p-chloronitrobenzene (42) and m-dinitrobenzene (43) over gold catalysts. The rate of nitro-group hydrogenation was concluded to be governed by gold particle size, with a general rate increase observed as $\mathrm{d}_{\mathrm{Au}}$ decreased.

\subsection{Selective hydrogenation of alkyne and alkadiene impurities in $\mathrm{C}_{2}-\mathrm{C}_{6}$ alkene streams}

Of particular interest to this review is the partial selective hydrogenation of hydrocarbons with multiple unsaturation (i.e. alkynes and alkadienes) to produce alkenes. Industrially this process employs supported palladium or palladium-silver catalysts, but more recently the unique selectivity of gold for the hydrogenation of triple bonds in alkyne-alkene mixtures has suggested it as an attractive alternative for the hydrorefining of steam cracker product cuts $(20,44)$.

The selective hydrogenation of multiple-unsaturated hydrocarbons such as those containing a $\mathrm{C} \equiv \mathrm{C}$ bond or pairs of $\mathrm{C}=\mathrm{C}$ bonds is carried out for the purification of 1-olefin streams. This process is industrially important for the production of 1-alkenes for use as co-monomers in polymer production. Commercially used supported palladium or palladium-silver catalysts are not always 100\% selective and the formation of oligomers or 'green oil' shortens the life of the industrial catalyst. In this process alkyne and/ or alkadiene impurities are partially hydrogenated to the desired 1-olefin, without significant hydrogenation of the product to the saturated species (alkane).

The selectivity problem of this process is that the desired product is the intermediate. Gold catalysts are unique in that they are able to produce the alkene with almost total selectivity due to the stronger adsorption of the alkyne/alkadiene compared to the alkene (44). Following partial hydrogenation to the alkene, this stronger adsorption inhibits the readsorption of the alkene and further hydrogenation to the alkane. Total hydrogenation to the alkane will only occur once the concentration of multipleunsaturated species is low enough to allow the adsorption of the alkene $(44,45)$. In the case of palladium catalysts the high selectivity observed for ethyne hydrogenation is due to the partial coverage of the surface by oligomers (46), and not to the preferred adsorption of the alkyne and it is not clear to what extent this effect may operate with gold catalysts.

\subsection{1 $C_{2}$ hydrocarbons}

Ethene has the highest production rate of any petrochemical product in the world. The $\mathrm{C}_{2}$ cut from steam cracking may contain $0.5-3 \%$ ethyne (47) that must be removed to produce polymer grade ethene, which cannot contain more than 5 ppm ethyne. As such, the selective partial hydrogenation of ethyne in ethene is a significant industrial process.

Studies using various hydrocarbons have reported that the hydrogenation selectivity of palladium catalysts can be enhanced by the addition of a second metal such as Cu (48), Ag (49-51) and Au (51). Industrial interest in these bimetallic catalysts is apparent from a number of examples in the patent literature (52-55). In 2002, Sarkany and co-workers (56) investigated the selective deposition of gold onto $\mathrm{Pd} / \mathrm{SiO}_{2}$ for acetylene hydrogenation. A decrease in the carbon coverage and enhanced ethene selectivity was observed for the Pd-Au catalysts.

Jia and co-workers (20) first reported monometallic gold as an alternative to palladium for the removal of ethyne via catalytic hydrogenation. The Au/ $\mathrm{Al}_{2} \mathrm{O}_{3}$ catalysts were $100 \%$ selective to ethene in the temperature range $313-523 \mathrm{~K}$, with total hydrogenation to ethane occurring only above 573 $K$. The results showed the dependence of catalytic activity on gold particle size, with a maximum activity at $3 \mathrm{~nm}$.

Subsequently, Choudhary et al (57) compared the performance of monometallic $\mathrm{Au} / \mathrm{TiO}_{2}$ and $\mathrm{Pd} / \mathrm{TiO}_{2}$ with bimetallic $\mathrm{Au}-\mathrm{Pd} / \mathrm{TiO}_{2}$. Results confirmed the gold particle size dependence noted by Jia et al. (20). Although the $\mathrm{Au} / \mathrm{TiO}_{2}$ catalysts were highly selective to ethene at high conversion, the activity was poor when compared to $\mathrm{Pd} / \mathrm{TiO}_{2}$ and a significant 
deactivation overtimewas observed. This deactivation was attributed to coke deposition. However, the Pd-promoted Au catalyst showed superior stability compared to the monometallic gold catalysts, as well as high ethene selectivity compared to the $\mathrm{Pd} / \mathrm{TiO}_{2}$ catalyst. The enhanced ethene selectivity was attributed to a close interaction between gold and palladium on the catalyst surface.

In 2008, Azizi and co-workers (58) investigated the hydrogenation of ethyne and formation of carbonaceous deposits using $\mathrm{Au} / \mathrm{CeO}_{2}$. The catalysts were prepared by direct anionic exchange, which produced catalysts with an average gold particle size of $2 \mathrm{~nm}$. $\mathrm{H}_{2} / \mathrm{C}_{2} \mathrm{H}_{2}$ ratios between 3 and 60 were tested in the temperature range $300-673 \mathrm{~K}$. An ethene selectivity of $100 \%$ was observed for all $\mathrm{H}_{2} / \mathrm{C}_{2} \mathrm{H}_{2}$ ratios up to $573 \mathrm{~K}$. Below this temperature a carbonaceous deposit formed which led to a slow deactivation but did not alter selectivity. Above $573 \mathrm{~K}$ deactivation occurred swiftly and was accompanied by decreased selectivity.

\subsection{2 $\mathrm{C}_{3}$ hydrocarbons}

Lopez-Sanchez and Lennon (59) considered $\mathrm{Au} / \mathrm{TiO}_{2}$ and $\mathrm{Au} / \mathrm{Fe}_{2} \mathrm{O}_{3}$ for the selective hydrogenation of propyne. The Au/ $\mathrm{TiO}_{2}$ catalysts were 100\% selective to the formation of propene, although

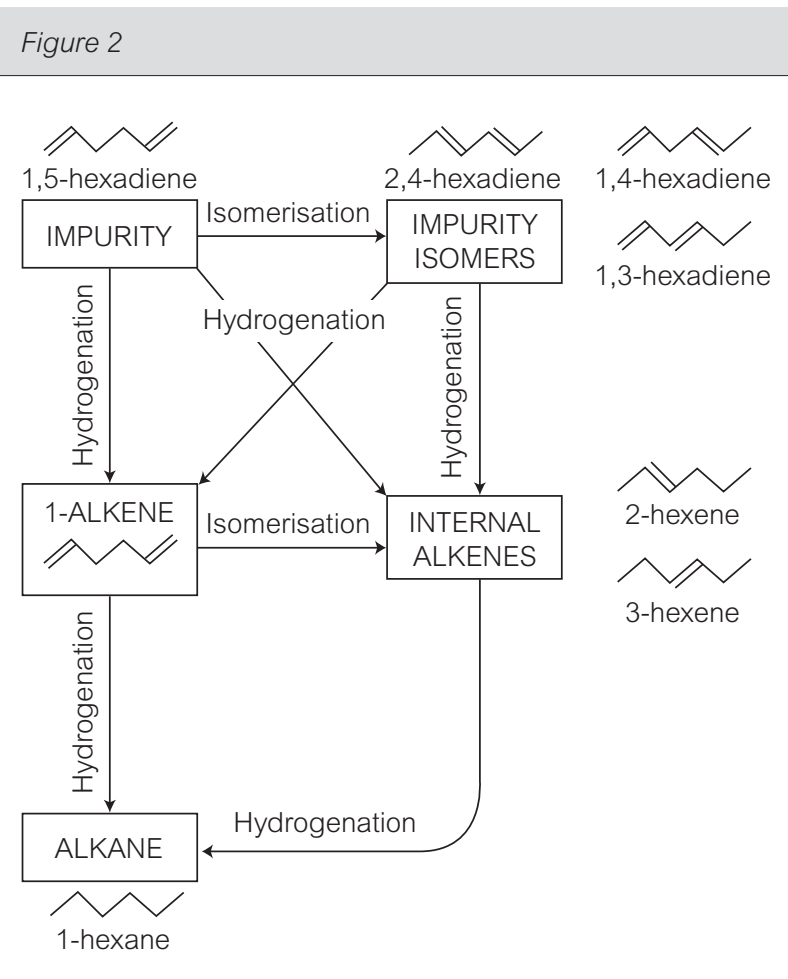

Reaction scheme for 1,5-hexadiene hydrogenation progressive deactivation was observed. Initially the $\mathrm{Au} / \mathrm{Fe}_{2} \mathrm{O}_{3}$ catalysts behaved similarly to the Au/ $\mathrm{TiO}_{2}$ catalysts, but following 4 months of ageing decreased propene selectivity was observed, accompanied by the absence of deactivation. Pre-treament at $663 \mathrm{~K}$ was able to recover the propene selectivity to $100 \%$. The optimum temperature for propene formation was found to occur at $423 \mathrm{~K}$ for $\mathrm{Au} / \mathrm{TiO}_{2}$ and $523 \mathrm{~K}$ for $\mathrm{Au} / \mathrm{Fe}_{2} \mathrm{O}_{3}$, highlighting the differences in interaction between the gold metal and the support for the two catalysts.

Following this, Segura and co-workers (44) aimed to find the origin of the superior selectivity of gold in alkyne/alkene mixtures. DFT simulations using different palladium and gold models attributed the high selectivity to the preferential adsorption of $\mathrm{C} \equiv \mathrm{C}$ compared to $\mathrm{C}=\mathrm{C}$ at the edges of gold nanoparticles. In comparison, both $\mathrm{C} \equiv \mathrm{C}$ and $\mathrm{C}=\mathrm{C}$ are adsorbed on palladium. The simulations were demonstrated experimentally using $\mathrm{Au} / \mathrm{CeO}_{2}$ in mixtures of propyne and propene, selectivities of $80-95 \%$ were observed in the temperature range 473-573 K. The patent application (60) discloses the use of gold supported on a NiAl mixed oxide support for selective propyne hydrogenation, where selectivities to propene above $90 \%$ at high (>90\%) conversion were observed for several of the catalysts.

\subsection{3 $C_{4}$ and $C_{5}$ hydrocarbons}

The selective hydrogenation of $\mathrm{C}_{4}+$ streams becomes increasingly complicated due to the issue of doublebond isomerisation. Both the 1-olefin and higher unsaturated impurities may isomerise, creating a more complex reaction pathway as illustrated in Figure 2 opposite.

Gold catalysed hydrogenation was first reported by Bond et al. (2-4) using $\mathrm{C}_{4}$ and $\mathrm{C}_{5}$ hydrocarbons. $\mathrm{Au} / \mathrm{SiO}_{2}, \quad \mathrm{Au} / \gamma-\mathrm{Al}_{2} \mathrm{O}_{3}, \quad \mathrm{Au} /$ boehmite, prepared by impregnation, catalysed the hydrogenation of 1-3-butadiene and 2-butyne, with butene as the sole product (2). In subsequent studies 1-pentene hydrogenation and isomerisation were tested, $\mathrm{Au} / \mathrm{SiO}_{2}$ and $\mathrm{Au} / \gamma-\mathrm{Al}_{2} \mathrm{O}_{3}$ catalysed the hydrogenation to pentane at $373 \mathrm{~K}(3,4)$. The $\gamma-\mathrm{Al}_{2} \mathrm{O}_{3}$ supported catalysts were less active in hydrogenation. The activity of $\mathrm{Au} / \mathrm{SiO}_{2}$ showed a dependence on the metal concentration and passed through a minimum at $1 \mathrm{wt} \%$ Au. Deactivation was observed over time and attributed to the formation of a carbonaceous residue. Only high gold loaded catalysts (5 wt\%) catalysed simultaneous hydrogenation to pentane and isomerisation to 2-pentene. The absence of 
double bond migration during the hydrogenation of pentene on $\mathrm{Au} / \mathrm{SiO}_{2}$ with low Au loadings illustrates that alkyl reversal does not occur when no site for accepting an $\mathrm{H}$ atom is readily available.

Subsequently Buchanan and Webb (5) used Au/ $\gamma$ $\mathrm{Al}_{2} \mathrm{O}_{3}$ to study the reaction of 1-3-butadiene with hydrogen and deuterium. Complete selectivity to butene was observed, although activity was lower than conventional palladium and platinum catalysts. Again the gold catalysts showed a progressive deactivation over time.

Okumura et al (61) investigated the hydrogenation of 1,3-butadiene over $\mathrm{Au} / \mathrm{SiO}_{2}, \quad \mathrm{Au} / \mathrm{Al}_{2} \mathrm{O}_{3}$ and $\mathrm{Au} / \mathrm{TiO}_{2}$ in order to determine the effect of gold particle size and choice of support. In contrast to previous findings, it was found that the catalytic activity was not notably affected by the size of gold particles and the choice of support.

A very high intrinsic activity in the hydrogenation of 1,3-butadiene was exhibited for gold clusters prepared by Hensen and Guan (62) via leaching a $\mathrm{Au} / \mathrm{CeO}_{2}$ catalyst with $\mathrm{NaCN}$ and, in contrast to other authors $(46,60)$, Hensen and Guan (62) report the hydrogenation of dienes to be strongly structure sensitive.

Zhang et al. $(63,64)$ used $\mathrm{Au} / \mathrm{ZrO}_{2}$ to investigate the effects of $\mathrm{Au}^{3+} / \mathrm{Au}^{0}$ ratio on 1,3-butadiene hydrogenation. The study reported that metallic $\mathrm{Au}^{0}$ atoms at the surface of the gold particles were not the only active catalytic sites and that isolated $\mathrm{Au}^{3+}$ ions were the most active. The co-existence of $\mathrm{Au}^{0}$ with $\mathrm{Au}^{3+}$ led to a decrease in activity and altered the selectivity of the catalyst. The study concluded that the $\mathrm{Au}^{3+} / \mathrm{Au}^{0}$ ratio may be an important consideration for the development of gold hydrogenation catalysts.

Recent research considering hydrogenation as a method of 1-olefin purification has moved towards more realistic conditions, where the multiply unsaturated impurity is present in small amounts in the olefin stream. To this effect, Hugon and co-workers $(47,65)$ investigated the selective hydrogenation of 1,3-butadiene in propene by gold supported on zirconia, ceria, alumina and titania. In contrast to the results of Zhang et al $(63,64)$ the $\mathrm{Au}^{3+}$ species was inactive and only became active once reduced to $A u^{0}$ under the reactant stream. Furthermore, the presence of propene did not adversely affect the reaction of butadiene hydrogenation. Hydrogen dissociation is reported by Hugon and co-workers (65) to be responsible for the low activity of gold since it is the rate limiting step, however, the high selectivity of the gold catalysts was attributed to the different temperatures at which the alkene and alkadiene hydrogenation reaction occurs, i.e. $0.1 \%$ conversion at $573 \mathrm{~K}$ and $100 \%$ at $\mathrm{T}<443 \mathrm{~K}$ respectively. Moreover, in the selective hydrogenation of butadiene on gold, the (Z)-2-butene product has been found to be favoured over the (E)-2-butene product $(47,61,63)$. This is an unexpected result based on the fact that (E)-butadiene is thermodynamically more stable than the (Z)butadiene and (E)-butadiene is predominantly the product in the hydrogenation of 1,3-butadiene on Pd- or Pt- based catalysts (47). However, DFT calculations by Zhang and co-workers (66) show that the (Z)-1,3-butadiene can be preferably adsorbed on the low coordinated edges and corners of gold nanoparticles as compared to the (E)-1,3-butadiene - making the adsorption of the (Z)-isomer thermodynamically favourable. Furthermore, isomerisation of (E)-butadiene to (Z)-butadiene is kinetically favoured as determined by transition state calculations and the ratio of $(Z) /(E)$ isomers was found to be highly sizedependent (66).

\subsection{4 $C_{6}$ hydrocarbons}

The majority of work around the hydrogenation of $\mathrm{C}_{6}$ hydrocarbons has focused on cyclohexene. Unlike other work reviewed in this paper this is not a reaction where one functional group is selectively hydrogenated in preference over another.

Erkelens et al. (67) investigated reactions of cyclohexene with hydrogen using gold film at 469-616 $\mathrm{K}$. Cyclohexene reacted to yield both cyclohexane and benzene, with the yield of benzene increasing with temperature. The exchange of cyclohexene with deuterium took place stepwise with an activation energy of $27 \mathrm{~kJ} \mathrm{~mol}^{-1}$ between 423 and $513 \mathrm{~K}$. The reaction of cyclohexene over gold powder catalyst between 478 and $558 \mathrm{~K}$ has also been investigated (68) and similar results were observed. The activation energy for hydrogenation of cyclohexene to cyclohexane was found to be less than that for the dehydrogenation to benzene, activation energies were 61 and $92 \mathrm{~kJ} \mathrm{~mol}^{-1}$ respectively. Over gold powder the yield of benzene was enhanced by the absence of hydrogen, as well as by a low partial pressure of oxygen, while high partial pressures of hydrogen enhanced the yield of cyclohexane. 
Wood et al. (69) studied the mechanism of catalytic hydrogenation of cyclohexene over a gold film electroplated on a palladium-silver alloy thimble and assigned an activation energy of $21 \mathrm{~kJ} \mathrm{~mol}^{-1}$ to the reaction. The rate of hydrogenation of cyclohexene on a metal surface was suggested to be dependent on the square of the hydrogen adatom concentration, and independent of the partial pressures of both the olefin and cyclohexane. Hydrogen adatoms were delivered to the gold surface by hydrogen gas contacting the palladium-silver surface, diffusing through the alloy and emerging on the gold surface in the chemisorbed state. This illustrates that hydrogen atoms are as soluble in $\mathrm{Au}$ as $\mathrm{Pd}$, the problem being to effect their dissociation.

Further studies by Wood et al. (70) investigating gas-phase hydrogenation of 1-butene and cyclohexene over a gold surface at $383 \mathrm{~K}$ concluded that hydrogenation rates were first order in alkene pressureand second order in chemisorbed hydrogen. When a mixture of the gases was measured, the catalyst did not distinguish between the two alkenes during the hydrogenation process and the total rate of hydrogenation was found to be the sum of the individual rates.

Mukherjee et al. (71) synthesized gold nanoparticles on an amorphous silica support which obtained 100\% selectivity for the hydrogenation of cylcohexene to cyclohexane and observed that the catalytic activity depends on the size of the nanoparticles.

Gao and Angelici (72) prepared a catalyst with $\mathrm{Rh}_{2} \mathrm{Cl}_{2}(\mathrm{CO})_{4}$ adsorbed directly onto gold powder as well as gold catalysts that contained tethered ligands 2-(diphenylphosphino)ethane-1-thiol or methyl 2-mercaptonicotinate. The catalysts were all active for 1-hexene hydrogenation under mild conditions of $313 \mathrm{~K}$ and $1 \mathrm{~atm}$ of hydrogen. The process was a batch process which ran over 2 hours. They concluded that a form of Rh metal on Au is the catalytically active species.

Wu et al. (73) studied the adsorption and reaction of cyclohexene, 1-hexene and benzene on a nascent gold surface formed by friction. Investigations were carried out in an adsorption test apparatus in high vacuum at room temperature. The study also included investigations on a nascent Pd-Ag alloy for comparative purposes. The nascent gold surface showed catalytic activity for the hydrogenation of cyclohexene and 1-hexene, and for the dehydrogenation of the olefins and benzene. The catalytic activity for the hydrogenation of 1-hexene to hexane was observed to be higher than that of cyclohexene to cyclohexane, and the adsorption rate of the olefins was observed to be higher than that of benzene. Although cyclohexene, 1-hexene and benzene dehydrogenated on the nascent Pd$\mathrm{Ag}$ alloy surface, the desorption of hydrogenation products was not detected.

\section{Concluding remarks}

Supported gold catalysts have shown potential for the chemoselective hydrogenation of $\alpha, \beta$-unsaturated aldehydes and the selective partial hydrogenation of alkyne, alkadiene and alkene $\mathrm{C}_{2}-\mathrm{C}_{6}$ hydrocarbon streams. These reactions each present a unique selectivity challenge for which gold has displayed promising results. Much remains uncertain with regard to the effects of particle size and influence of support on the activity and selectivity of the gold catalysts. Studies have found contradicting results, particularly in terms of particle size. The selective partial hydrogenation of alkynes and alkadienes is commercially interesting for the purification of 1-olefin streams and research in this area is moving closer to realistic conditions, with the alkyne or diene impurity present only in small amounts in the olefin stream.

It seems clear that there is a promising future for gold catalysts in selective hydrogenation reactions: to quote from the recent 'Catalysis by Gold' book, "It is hard to understand why these very attractive properties [of gold for hydrogenation] have not been more fully exploited by the petrochemical industry" (15). 


\section{About the authors}

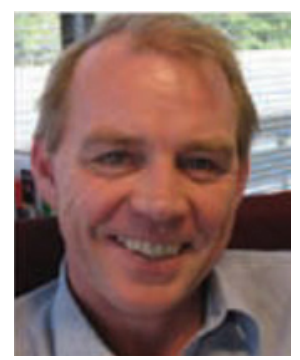

Professor Jack Fletcher is currently Head of Department of the Chemical Engineering Department at the University of Cape Town (UCT). His research focuses on heterogeneous catalysis, specifically in the following areas: Shape Selectivity in Zeolites and Molecular Sieves, Phenols and Derivatives, Hydrocracking and Catalysis by Gold.

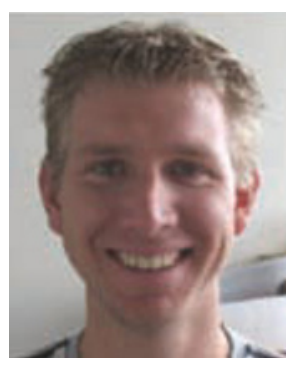

Stephen Roberts is currently the Industrial Research Manager in the Chemical Engineering Department at UCT. He graduated as a chemical engineer from UCT, where he also completed his postgraduate studies. Following this he worked at Mintek, South Africa's national mineral research organisation, in the field of gold catalysis.

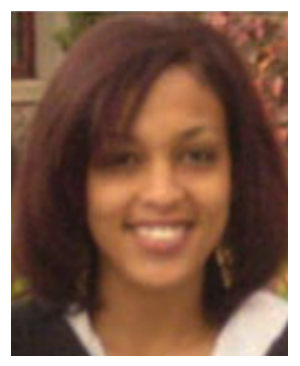

Melissa Julius is currently a PhD student in the Department of Chemical Engineering at UCT, She is focusing on the purification of 1-hexene via gold-based selective catalytic hydrogenation. She completed her MSc on similar work in 2008. Her work has been funded by Mintek, NRF, UCT and Sasol.

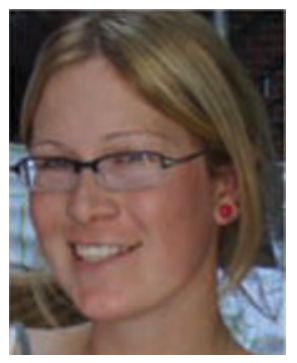

Lynsey McEwan is a MSc student at the Department of Chemical Engineering at UCT, currently writing her thesis on the use of gold catalysts in the selective hydrogenation of impurities in 1-hexene product streams. Her thesis was funded by Mintek and UCT. She graduated as a chemical engineer from UCT in 2007.

\section{References}

1 G.C. Bond and D.T. Thompson, Catal. Rev. Sci. Eng., 41(3\&4), 1999, 319-388

2 G.C. Bond, P.A. Sermon, G. Webb, D.A. Buchanan and P.B. Wells, J. Chem. Soc. Chem. Commun., 1973, 444-445

3 G.C. Bond and P.A. Sermon, 1973, Gold Bulletin, 64

4 P.A. Sermon, G.C. Bond and P.B. Wells, J. Chem. Soc., Faraday Trans., 1979, 75, 385
5 D.A. Buchanan and G. Webb, J. Chem. Soc., Faraday Trans., 1974, 70, 134

6 G.C. Bond, Gold Bulletin, 1972, 51

7 D.I. Bradshaw, R.B. Moyes and P.B. Wells, J. Chem. Soc., Chem. Commun., 1975, 137

8 J.M.L. Penniger, Gold Bulletin, 1975, 83

9 M. Haruta, T. Kobayashi, H. Sano, N. Yamada, Chem. letter., 1987, 4, 405

10 M. Haruta, N. Yamada, T. Kobayashi and S. Iijima, J. Catal., 1989, 115 (2), 301-309

11 B. Nkosi, N.J. Coville and G.J. Hutchings, J. Chem. Soc., Chem.Commun., 1988, 71

12 B. Nkosi, N.J. Coville and G.J. Hutchings, Appl. Catal., 1988, 43, 33

13 B. Nkosi, N.J. Coville, G.J. Hutchings, M.D. Adams, J. Friedl and F. Wagner, J. Catal., 1991, 128, 366

14 B. Nkosi, M.D. Adams, N.J. Coville and G.J. Hutchings, J. Catal., 1991, 128, 378

15 G.C. Bond, C. Louis and D.T. Thompson, 'Catalysis by gold', Chapter 9 p 244

16 Graham J. Hutchings, Catal. Today, 2002, 72, 11-17

17 A. Sault, R. Madix, C. Campbell, Surface Science, 1986, 169, 347-356

18 L. Stobinski, L. Zommer, R. Dus., Applied Surface Science, 1999, 141, pp. 319-325

19 M. Vannice, S. Lin, Catal. Letters, 1991, 10, 47

20 J. Jia, K. Haraki, J.N. Kondo, K. Domen and K. Tamaru, J. Phys. Chem. B, 2000, 104, 11153-11156

21 E. Bus, J.T. Miller and J.A. van Bokhoven, J. Phys. Chem. B, 2005, 109, 14581-14587

22 E. Bus and J.A. van Bokhoven, Phys. Chem. Chem. Phys., 2007, 9, 2894-2902

23 P. Serna, M. Boronat, P. Concepcion, A. Corma, S. Gonzalez and F. Illas, J. Am. Chem. Soc., 2007, 129, 16230

24 M. Boronat, F. Lllas, A. Corma, J. Phys. Chem. A, 2009a, 113, 3750

25 M. Boronat, P. Concepcion, A. Corma, J. Phys. Chem. C, 2009b, 113, 16772

26 T. Fujitani, I. Nakamura, T. Akita, M. Okumura, M. Haruta, Angew. Chem. Int. Ed., 2009, 48, 9515-9518

27 M. Patterson and M. Weaver, J. Phys. Chem., 1985, 89 5046-5051

28 H. Feilchenfeld and M. Weaver, J. Phys. Chem., 1989, 93, 4276-4282

29 P. Claus, Appl. Catal. A: General, 2005, 291, 222-229

30 G.J. Hutchings, Catal. Today, 2008, 138, 9-14

31 J.E. Bailie and G.J. Hutchings, J. Chem. Soc. Chem. Commun., 1999, 2151-2152

32 J.E. Bailie, H.A. Abdullah, J. Anderson, C.H. Rochester, N.V. Richardson, N. Hodge, J-G. Zhang, A. Burrows, C.J. Kiely, G.J. Hutchings, Phys. Chem. Chem. Phys., 2001, 3, 4113

33 C. Mohr, H. Hofmeister, and P. Claus, Journal of Catalysis, 2003, 213, 86-94 
34 C. Mohr, H. Hofmeister, J. Radnik, and P. Claus, J. Am. Chem. Soc., 2003, 125, 1905-1911

35 P. Claus, H. Hofmeister, C. Mohr, Gold Bulletin, 2004, 37, 3\&4, 181-186

36 J. Lenz, B.C. Campo, M. Alvarez, M.A. Volpe, J. Catal., 2009, 267, 50-56

37 F. Coloma, J. Coronado, C. Rochester, J. Anderson, Catalysis Letters, 1998, 51, 155-162

38 M. Vannice, Topics in Catalysis, 1997, 4, 241-248

39 Y. Chen, J. Qiu, X. Wang, J. Xiu, J. Catal., 2006, 242, 227-230

40 A. Corma and P. Serna, Science, 2006, 313, 332

41 A. Corma, P. Serna, and H. Garcia, J. Am. Chem. Soc., 2007, 129, 6358-6359

42 F. Cardenas-Lizana, S. Gomez-Quero, N. Perret, M.A. Keane, Gold Bulletin, 2009, 422

43 F. Cardenas-Lizana, S. Gomez-Quero, H. Idriss, M.A. Keane, J. Catal., 2009, 268, 223-234

44 Y. Segura, N. López, J. Pérez-Ramírez, J. Catal., 2007, 247, 383-386

45 Á. Molnár, A. Sárkány, M. Varga, J. Molecular Catal. A: Chemical, 173, 2001, 185-221

46 A. Borodzinski, G.C. Bond, Catalysis Reviews, 48:91-144, 2006

47 A. Hugon, L. Delannoy and C. Louis, Gold Bulletin, 41, 2008, 127

48 L. Guczi, Z. Schay, G. Stefler, L.F. Liotta, G. Deganello and A.M. Venezi, J. Catal., 182, 1999, 456-462

49 Q. Zhang, J. Li, X. Liu, Q. Zhu, Applied Catalysis A: General, 197, 2000, 221-228

50 E.A. Sales, B. Benhamida, V. Caizergues, J.-P. Lagier, F. Fiévet, F. Bozon-Verduraz, Appl. Catal. A: Gen., 172, 1998, 273-283

51 G.C. Bond and A.F. Rawle, J. Molec. Catal. A: Chemical, 109, 1996, 261-271

52 J.P. Boitiaux and J. Cosyns, US Pat., 4490481, 1984

53 J.P. Boitiaux and J. Cosyns, US pat., 4533779, 1984

54 S.A. Blankenship, A. Rokicki and J.A. Perkins, US pat., 6509292, 2003
55 Y. Zhang and S.J. Golden, WO/2006/009988, 2006

56 A. Sárkány, A. Horváth and A. Beck, Appl. Catal. A: General, 229, 2002, 117-125

57 T.V. Choudhary, C. Sivadinarayana, A.K. Datye, D. Kumar, and D.W. Goodman, Catal. Letters, 86 Nos. 1-3, March 2003

58 Y. Azizi, C. Petit, V. Pitchon, J. Catal., 256, 2008, 338-344

59 J.A. Lopez-Sanchez, D. Lennon, Appl. Catal. A: General, 291, 2005, 230-237

60 J. Pérez-Ramirez, Y. Segura, EP 1970 117, 17.09.2008, Bulletin 2008/38

61 M. Okumura, T. Akita, M. Haruta, Catal. Today, 74, 2002, 265-269

62 Y. Guan and E.J.M. Hensen, Phys. Chem. Chem. Phys., 2009, 11, 9758-9582

63 X. Zhang, H. Shi, B.-Q. Xu, Angew. Chem. Int. ed., 44, 2005, 7132

64 X. Zhang, H. Shi, B.-Q. Xu, Catalysis Today, 122, 2007, 330-337

65 A. Hugon, L. Delannoy, C. Louis, Gold Bulletin, 2009, 42 No 4, 310

66 X-F. Yang, A-Q. Wang, Y-L. Wang, T. Zhang, J. Li, J. Phys. Chem. C, 2010, 114, 3131-3139

67 J. Erkelens, C. Kemball and K. Galwey, Trans. Faraday Soc., 1963, 59, 1181

68 M. Boudart and R. Chambers, Journal of Catalysis, 5, 1966, 517-528

69 B. Wood and H. Wise, Journal of Catalysis, 5, 1966, 135-145

70 B. Wood, H. Wise and S. Inami, Journal of Catalysis, 13, 1969, 397

71 P. Mukherjee, C. Patra, A. Ghosh, R. Kumar and M. Sastry, Chem. Mater., 14, 2002, 1678-1684

72 H. Gao and R. Angelici, Can. J. Chem., 79, 5-6, 2001, 578-586

73 X. Wu, N. Kobayashi, H. Nanao and S. Mori, Tribology Letters, 2005, 18, No. 2, 239-244 